\title{
Even Mode Network Model for Multi-band and Compact Modified Rectangular Microstrip Antennas
}

\author{
Amit A. \\ Deshmukh \\ EXTC, DJSCOE \\ Vile - Parle (W), \\ Mumbai, India
}

\author{
Tejal A. Tirodkar \\ EXTC, DJSCOE \\ Vile - Parle (W), \\ Mumbai, India
}

\author{
Ankita R. Jain \\ EXTC, DJSCOE \\ Vile - Parle (W), \\ Mumbai, India
}

\author{
K. P. Ray \\ SAMEER, IIT \\ Campus, Powai \\ Mumbai, India
}

\begin{abstract}
The multi-port network model is a simpler tool to analyze microstrip antennas on thinner substrates. While analyzing modified shaped microstrip antennas, the multi-port network model consists of larger number of segments which increases the complexity of the model. In this paper, first multi-port network models of multi-band and compact modified rectangular microstrip antennas are discussed. Further by using the symmetry of multi-port network models, a simpler even mode network equivalent model is proposed. The even mode network model solves only half of the network and thereby reduces the complexity of the multi-port network model. It gives closer match with multi-port network model result in terms of resonance frequency, input impedance and voltage distribution.
\end{abstract}

\section{Keywords}

Rectangular microstrip antenna, Multi-port network model, Even mode network model, Multi-band microstrip antenna, Compact microstrip antenna

\section{INTRODUCTION}

The compact microstrip antenna (MSA) is realized either by placing the shorting post or plate along the zero field line at the fundamental patch mode or by cutting the slot at an appropriate position inside the patch [1,2]. The dual band and triple band MSAs are also realized either by placing an open circuit nearly quarter wavelength stub on the edges of the patch or by cutting the slot like U-slot and rectangular slots inside the patch, or by using the combination of slot and stub [3 - 5]. These compact and multi-band MSAs finds wide applications in mobile communications, Wi-Fi networking and in laptops. For analyzing MSAs different techniques based on the magnetic current model around the patch periphery or electric current model on the patch are available $[1,2]$. Out of them, multi-port network model (MNM) which is based upon the magnetic current model around the patch periphery, is an simpler and efficient tool for analyzing MSAs on thinner substrates $(h)\left(h<0.04 \lambda_{0}\right)[1,2]$. In MNM, fields inside the patch are modeled using the Green's function of the patch geometry and outside the patch they are modeled using radiation and surface wave conductance which accounts for radiation from the patch and the surface waves. For using MNM in modified shaped MSAs, the patch is first divided into regular shapes for which the Green's function is available and further by using either segmentation or de-segmentation technique, the input impedance of the composite configuration is calculated. Using the reported formulations in MN model, the voltage distribution around the patch periphery is calculated which is very useful in understanding the mode excitation at a given frequency. While using segmentation method in analyzing compact and multi-band MSAs, numbers of segments in their MN model are higher which increases the complexity of the network. The de-segmentation technique involves lesser number of segments in its $\mathrm{MN}$ model but it is relatively complex method as compared to the segmentation method.

When the MN model of MSA is symmetrical across the feed point axis then its equivalent even mode network model has been used to calculate the input impedance and voltage distribution around the patch periphery, and it gives closer match with the MN model result [6]. In this paper, first MNM and an even mode network models for RMSA are discussed. Further the MN models for compact slot cut RMSA like Hshaped and ring MSAs and dual and triple band slot cut and stub loaded RMSAs are proposed. By using the symmetry of MN models across the feed point axis, an even mode network models for compact as well as multi-band RMSAs are proposed. The even mode network model reduces the number of segments by half and thus reduces the complexity of the structure. Further it gives the same results in terms of resonance frequency, input impedance and voltage distribution to that given by their MN model. Thus for any complex shaped MSAs, which are symmetrical across feed point axis, their even mode model of the equivalent MN model can be solved. All the compact and multi-band RMSAs were first analyzed using IE3D software followed by MNM, even mode modeling [7]. In some of the cases, patch was fabricated and the measurement was carried out using R \& S vector network analyzer.

\section{MNM AND EVEN MODE ANALYSIS OF RMSA}

The RMSA and its MN model are shown in Fig. 1(a, b). In MN model, $\mathrm{N}_{\mathrm{a}}$ and $\mathrm{N}_{\mathrm{b}}$ ports are taken along the non-radiating and radiating edges, respectively. To account for fringing fields around the patch periphery, an edge extension length is added to the patch length and width $[1,2]$. The RMSA is loaded with the sum of radiation $\left(\mathrm{G}_{\mathrm{r}}\right)$ and surface wave $\left(\mathrm{G}_{\mathrm{s}}\right)$ conductance on the radiating and non-radiating edges. The $\mathrm{Z}$ matrix size for RMSA is $2\left(\mathrm{~N}_{\mathrm{a}}+\mathrm{N}_{\mathrm{b}}\right) \mathrm{x} 2\left(\mathrm{~N}_{\mathrm{a}}+\mathrm{N}_{\mathrm{b}}\right)$, corresponding to the connected ports. The segmentation method is used to calculate the input impedance $\left(\mathrm{Z}_{\mathrm{in}}\right)$. For RMSA with length (L) $=6 \mathrm{~cm}$ and width $(\mathrm{W})=4 \mathrm{~cm}$, on RTDuroid substrate $\left(\varepsilon_{\mathrm{r}}=2.33, \mathrm{~h}=0.159 \mathrm{~cm}, \tan \delta=0.001\right)$, with $\mathrm{N}_{\mathrm{a}}=14, \mathrm{~N}_{\mathrm{b}}=8$ and feed point at $\mathrm{x}_{\mathrm{f}}=0.7 \mathrm{~cm}$, input impedance $\left(\mathrm{Z}_{\text {in }}\right)$ and resonance frequency $\left(\mathrm{f}_{\mathrm{r}}\right)$ using MNM, are (42.12 j0.5) $\Omega$ and $1617 \mathrm{MHz}$, respectively. The corresponding 
simulated values using IE3D are, (38.02 - j 5.0) $\Omega$ and 1610 $\mathrm{MHz}$, respectively. The matrix size for $\mathrm{MN}$ model is $44 \mathrm{x} 44$. The MN model of RMSA is symmetrical across feed point axis. Hence only half of the portion is solved, which leads to its even mode network model as shown in Fig. 1(c). The RMSA width is reduced by half which reduces the number of ports along the radiating edge by half. This maintains the same port width to that used in MN model. The ports are taken along two radiating and one non-radiating edges. No ports are taken along the edge where the feed point is present. This reduces Z-matrix size to $\left(\mathrm{N}_{\mathrm{a}}+\mathrm{N}_{\mathrm{b}}\right) \mathrm{x}\left(\mathrm{N}_{\mathrm{a}}+\mathrm{N}_{\mathrm{b}}\right)$. The values of effective dielectric constant, loss tangent, and total conductance at each port are kept the same. They are not recalculated using the reduced width as width is reduced only for the computational simplicity. Further $\mathrm{Z}_{\text {in }}$ calculated by using even mode network is divided by two to obtain the input impedance as that will be given by its $\mathrm{MN}$ model. The $\mathrm{Z}_{\text {in }}$ and $\mathrm{f}_{\mathrm{r}}$ calculated by using even mode network model are (42.12 j0.7) $\Omega$ and $1617 \mathrm{MHz}$. The matrix size order is reduced to 22 $\mathrm{x} 22$ in the even mode network model. The $Z_{\text {in }}$ and frequency are very close to each other in the two methods and the size of the Z-matrix is reduced by a factor of 3 in the even mode method. This reduces computation time by more than half. Thus the above method is very useful in MNM analysis of complex shaped MSAs, which involves larger number of segments.
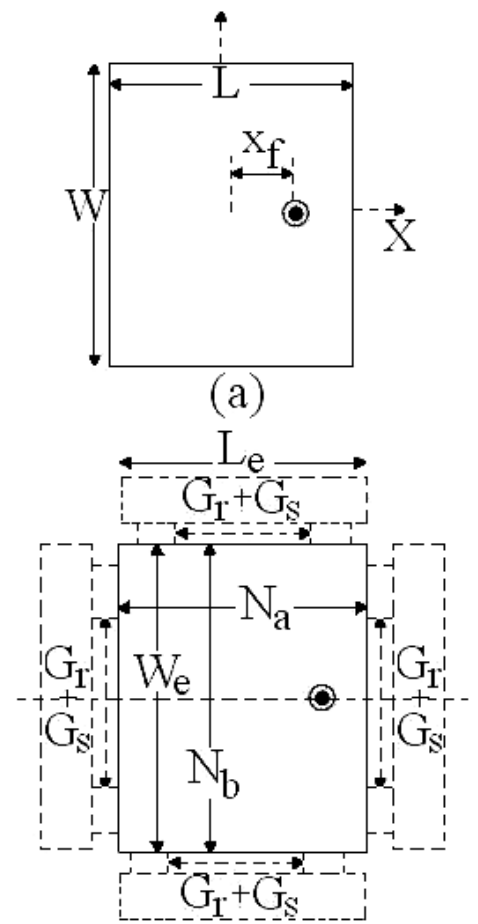

(b)

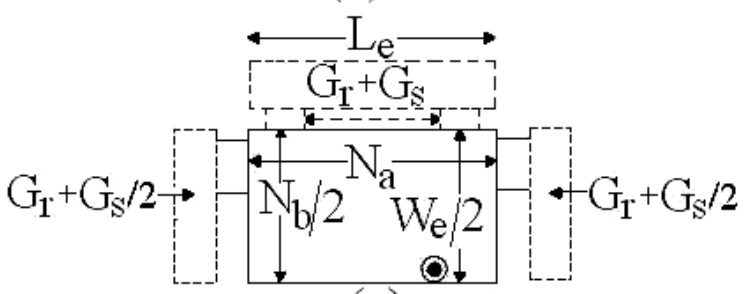

(c)

Fig. 1 (a) RMSA, its (b) MN and (c) even mode network model

\section{MNM AND EVEN MODE NETWORK MODEL FOR MULTI-BAND RMSAs}

More commonly dual band RMSA is realized by cutting the slot inside the patch. Here dual band pair of step slot cut RMSA is studied as shown in Fig. 2(a) [8]. The step slots are cut along the non-radiating edges of the RMSA. For the dimensions shown in figure, simulated dual frequencies and bandwidth (BW) are 661, $893 \mathrm{MHz}$ and $11,15 \mathrm{MHz}$, respectively, as shown in Fig. 2(c). The pair of step slot cut RMSA is analyzed using its MN model as shown in Fig. 2(b). The MSA is divided into six rectangular segments. The ' $\mathrm{C}$ ' are the ports taken along the edges of the individual segments and 'd' are the ports taken along segmented edges. The coaxial feed is represented by port ' $p$ '. Using the segmentation method the $Z_{\text {in }}$ is calculated and is shown in Fig. 2(c). The dual frequencies and BW's are 640 and $900 \mathrm{MHz}$ and 12 and $18 \mathrm{MHz}$, respectively. The $\mathrm{Z}_{\text {in }}$ at the two frequencies is (57.6 $-\mathrm{j} 2.2) \Omega$ and $(63-\mathrm{j} 8.3) \Omega$, respectively.
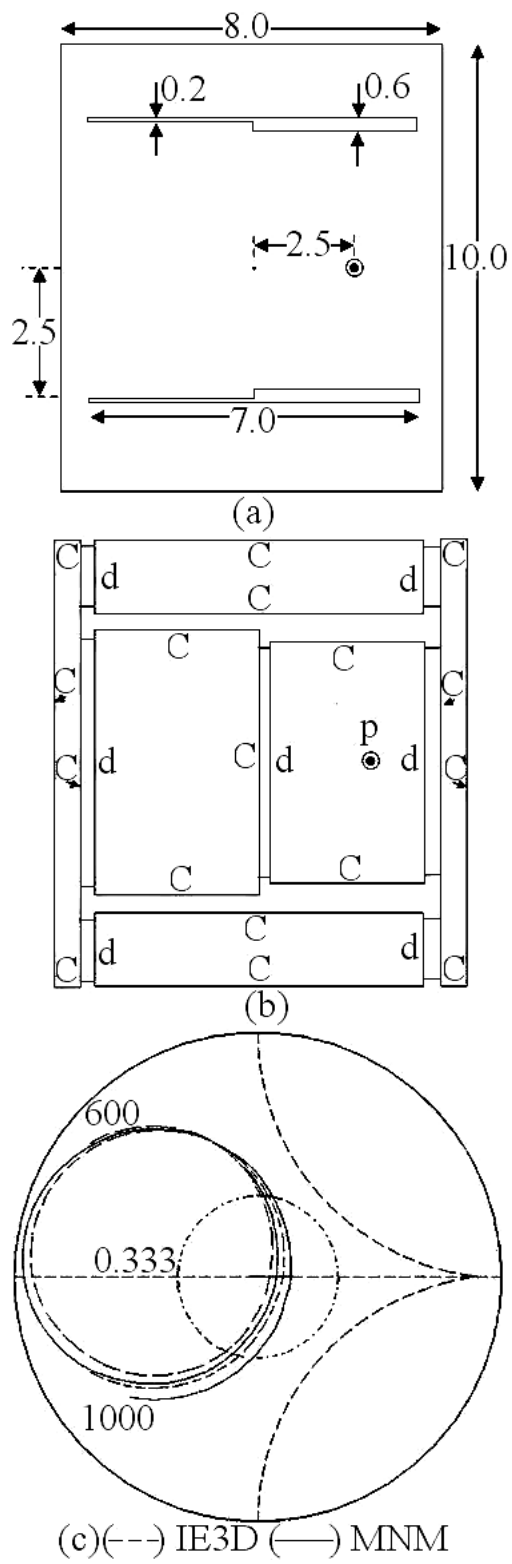

Fig. 2 (a) Dual band step slot cut RMSA, its (b) MN model and its (c) input impedance plot 
The voltage distribution across the RMSA and step slot is calculated by using the formulation reported in [1] and it is shown in Fig. 3(a-d). At first frequency $\left(f_{1}\right)$, a wavelength variation is present around the total slot length with voltage minima towards the shorted slot ends, indicating that $f_{1}$ is governed by the mode introduced by slot. The radiation pattern at $\mathrm{f}_{1}$ shows higher cross polarization levels due to the asymmetrical voltage distribution around the patch edges. At second frequency $\left(f_{2}\right)$, patch mode is dominant as half wavelength variation is present along the non-radiating edge of the patch as well as along the slot length. The radiation pattern at this frequency is in the broadside direction.

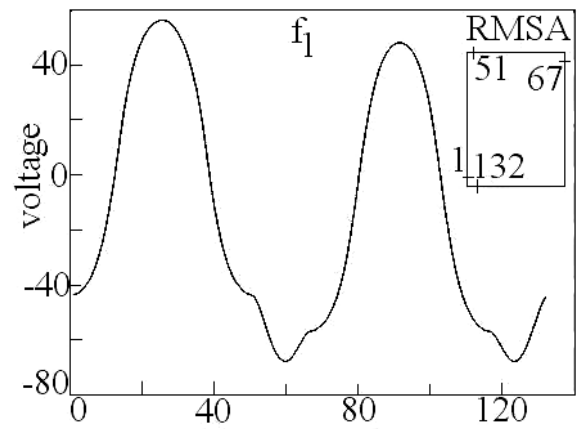

(a) port numbers

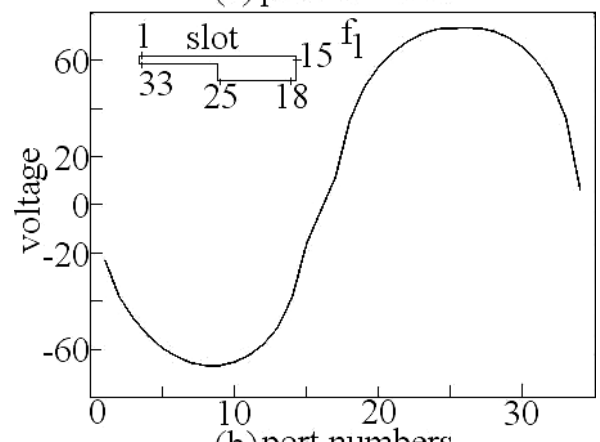

(b) port numbers

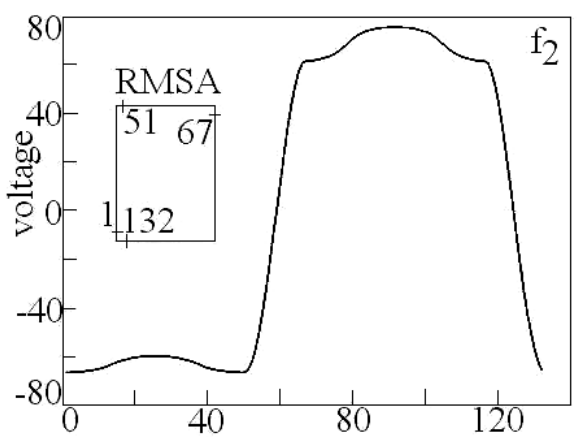

(c) port numbers

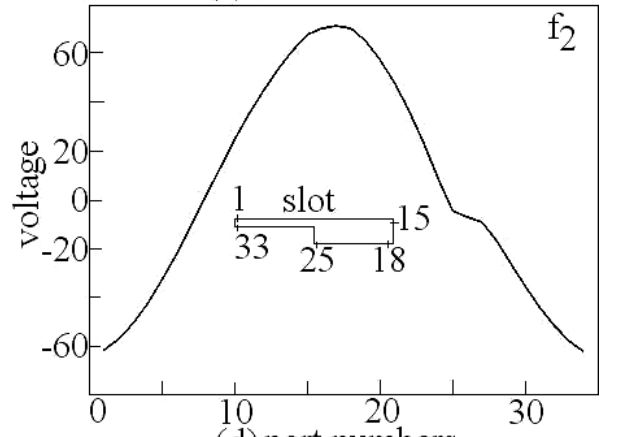

(d) port numbers

Fig. 3 (a - d) Voltage distribution for step slot cut RMSA
The MN model of step slot cut RMSA consist of six segments and its Z-matrix size is $312 \times 312$. The MN model of pair of step slot cut RMSA is symmetrical across the feed point axis, hence to reduce the number segments, an even mode network of step slot cut RMSA is proposed as shown in Fig. 4(a). The even mode model consist of five segments. The widths of the segments which are symmetrical across the feed point axis and the ports along them are reduced by half. The effective dielectric constant, loss tangent, radiation and surface wave conductance at each port are kept the same. Further by using segmentation method, $Z_{\text {in }}$ is calculated. Using even mode network, Z-matrix size is reduced to $156 \mathrm{x} 156$. The input impedance plot and voltage distributions at the two frequencies using even mode network are shown in Fig. 4(b) and $5(\mathrm{a}-\mathrm{d})$, respectively. The dual frequencies and BW's are 640 and $900 \mathrm{MHz}$ and 12 and $18 \mathrm{MHz}$, respectively. The $\mathrm{Z}_{\text {in }}$ at the two frequencies is $(54.9-\mathrm{j} 5.6) \Omega$ and $(59.8-\mathrm{j} 0.33) \Omega$, respectively. The resonance frequencies, input impedance and voltage distribution obtained using even mode model are similar to that obtained using MN model results. The results for step slot cut RMSA are given in Table 1.

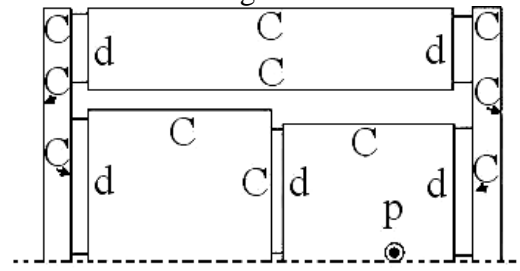

(a)

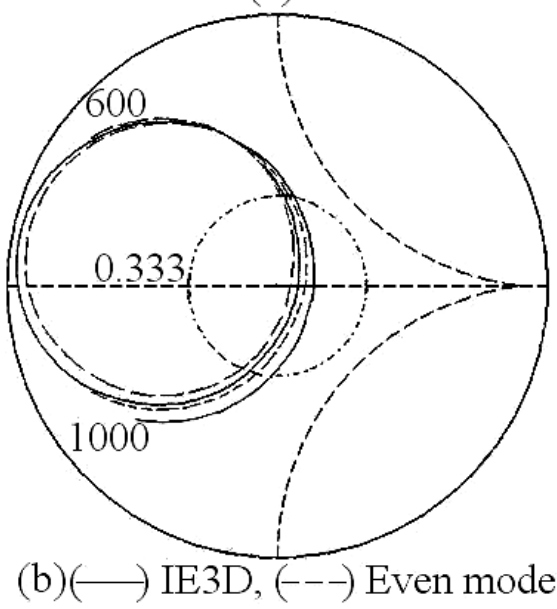

Fig. 4 (a) Even mode network and (b) input impedance plots for dual band step slot cut RMSA

The triple band RMSA is realized by using the combination of slot and stub inside the same patch and triple frequency stub loaded pair of rectangular slots cut RMSA is shown in Fig. 6(a). The triple frequencies are due to the mode introduced by the slot and the dual modes introduced by the stub. For the dimension shown in Fig. 6(a), the simulated triple frequencies and BWs are 675, 805 and $977 \mathrm{MHz}$ and 13, 11 and $12 \mathrm{MHz}$, respectively. The antenna response has been experimentally verified and measured frequencies and BWs are 713, 807 and $1002 \mathrm{MHz}$ and 10, 13 and $12 \mathrm{MHz}$, respectively. The triple band RMSA is analyzed using its MN model as shown in Fig. 6(b). The MN model consists of five rectangular segments. The number of ports along lengths and widths of each segment are selected as per the field variation along them. The stub is modeled as a separate segment. The impedance matrix for each segment is calculated by using the Green's function of rectangular patch and further by using segmentation 
technique, $\mathrm{Z}_{\text {in }}$ is calculated. The frequencies and BWs using $\mathrm{MN}$ model are 680, 784 and $978 \mathrm{MHz}$ and 11, 11 and 12 $\mathrm{MHz}$, respectively as shown in Fig. 6(c). To reduce the number of segments in the MN model, an even mode network model for triple band RMSA is proposed as shown in Fig. $6(d)$.

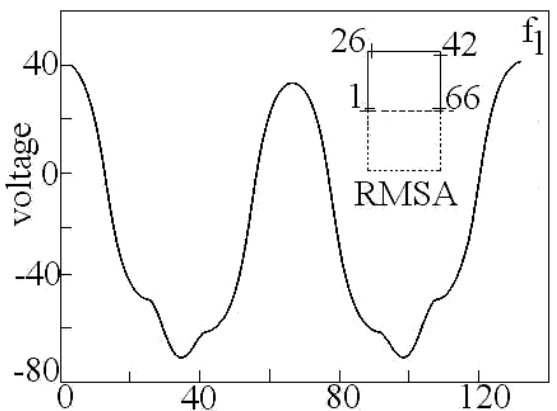

(a) port numbers

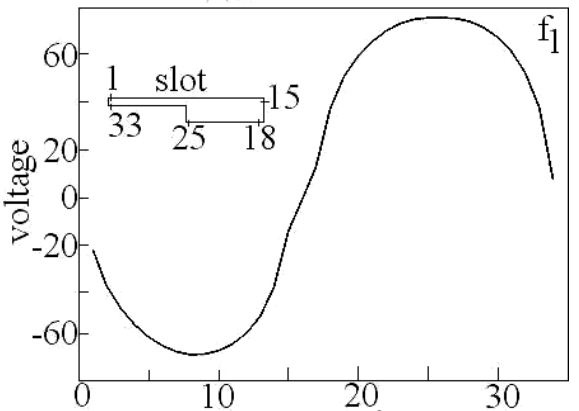

(b) port numbers

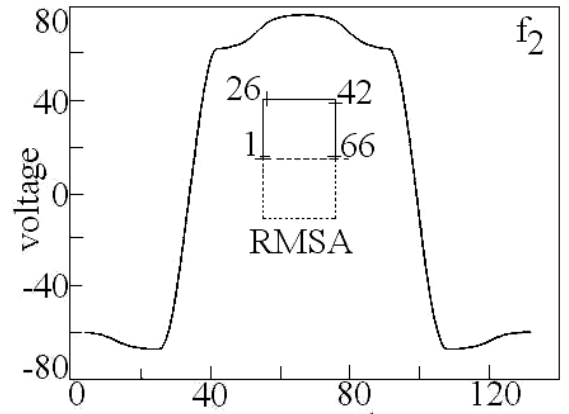

(c) port numbers

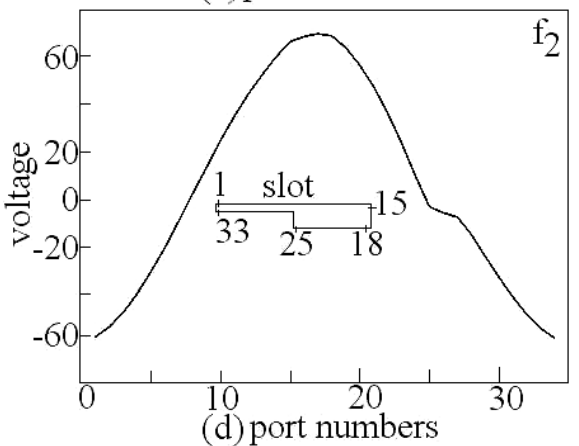

Fig. 5 (a - d) Voltage distribution for step slot cut RMSA using even mode network model

The even mode model consists of four rectangular segments and it also reduces the Z-matrix size for the equivalent network. Using the segmentation method the $Z_{\text {in }}$ is calculated. The frequencies and $\mathrm{BWs}$ calculated using even mode network are 681, 784 and $977 \mathrm{MHz}$ and 11, 12 and $12 \mathrm{MHz}$, respectively as shown in Fig. 6(c). These results are very close to that obtained using $\mathrm{MN}$ model results as well as the experimental results.
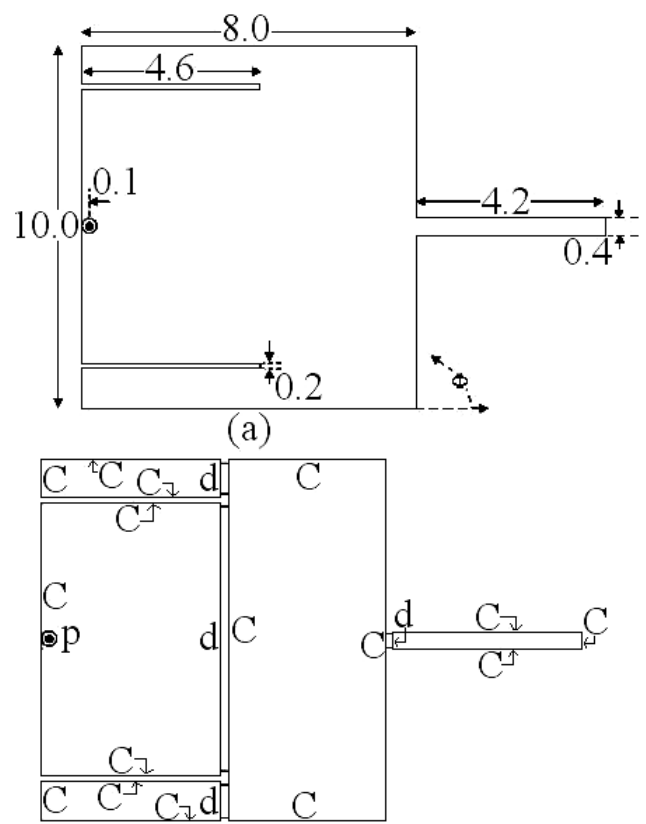

(b)

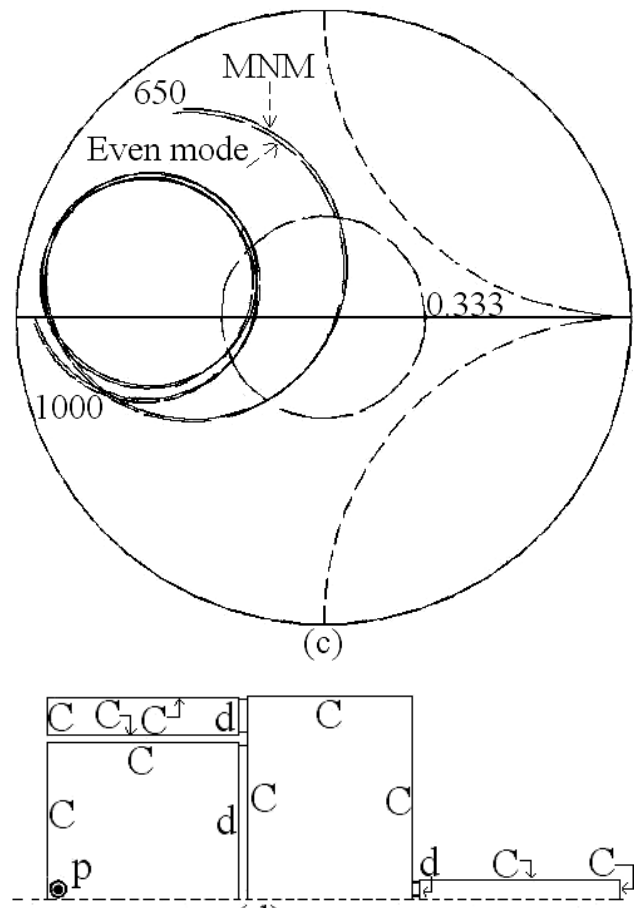

(d)

Fig. 6 (a) Pair of slot cut stub loaded RMSA, its (b) MN model, its (c) input impedance plot and its (d) even mode network model

Similarly triple band U-slot cut stub loaded RMSA as shown in Fig. 7(a) is analyzed using MNM and even mode network model as shown in Fig. 7(b, c). For the dimensions shown in Fig. 7(a), simulated triple frequencies and BWs are 745, 983 and $1185 \mathrm{MHz}$ and 13, 12 and $19 \mathrm{MHz}$ respectively. The MN model of the U-slot cut stub loaded RMSA consists of six rectangular segments and using the Green's function for rectangular geometry and the segmentation method, $\mathrm{Z}_{\text {in }}$ is calculated as shown in Fig. 7(d). The frequencies and BWs 
using MN model are 770, 952 and $1100 \mathrm{MHz}$ and 16, 18 and $22 \mathrm{MHz}$. The frequencies and BWs using even mode network are 771,953 and $1100 \mathrm{MHz}$ and 15, 17 and $23 \mathrm{MHz}$, respectively as shown in Fig 7(d).

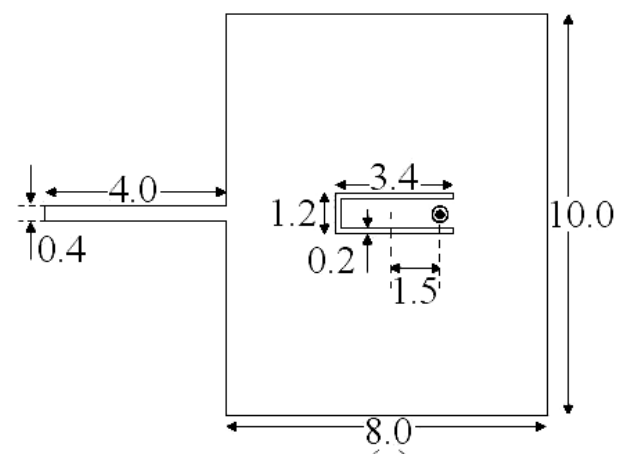

(a)

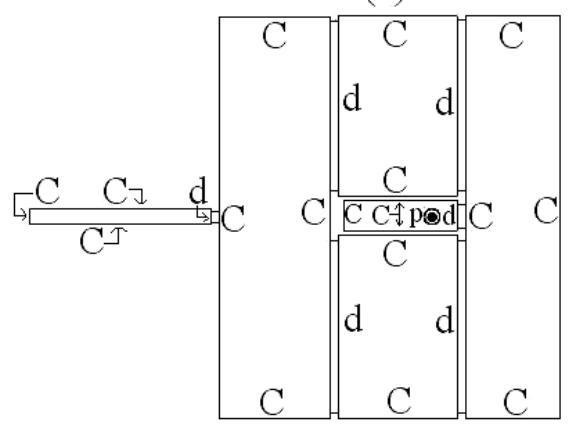

(b)

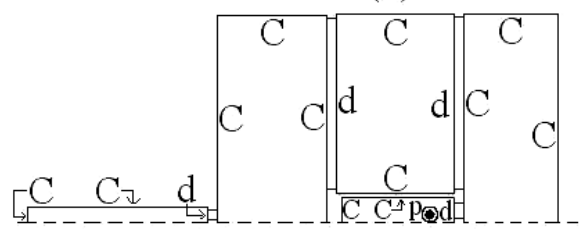

(c)

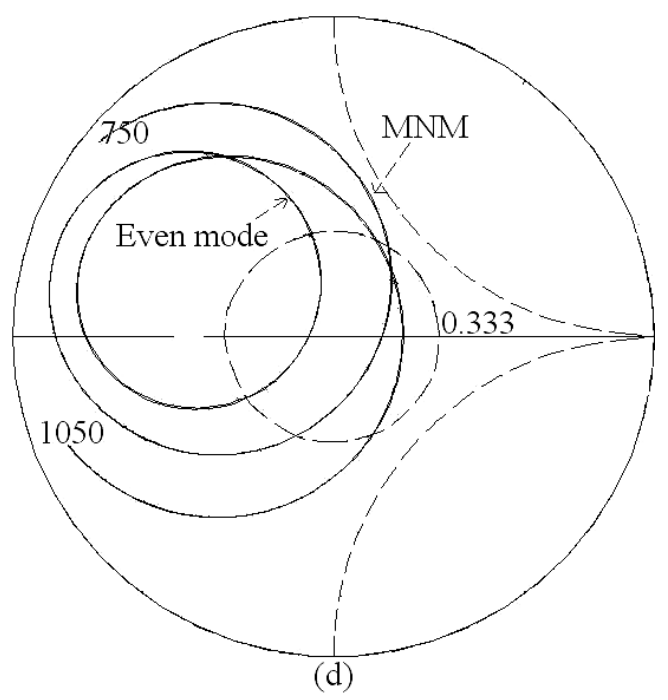

Fig. 7 (a) U-slot cut stub loaded RMSA, its (b) MN model, its (c) even mode network model and its (d) input impedance plot

For the dimension shown in Fig. 7(a), triple frequency response is experimentally verified. The measured frequencies and corresponding BWs are, 792, 993 and $1122 \mathrm{MHz}$ and 13, 13 and $18 \mathrm{MHz}$, respectively. Thus a close agreement is obtained between the simulated, MNM, even mode network and measured results.

\section{MNM AND EVEN MODE MODEL FOR COMPACT RMSAS}

The resonance frequency of RMSA $(\mathrm{L}=6.0 \mathrm{~cm}, \mathrm{~W}=4.0 \mathrm{~cm})$ on RT-Duroid substrate $\left(\varepsilon_{\mathrm{r}}=2.33, \mathrm{~h}=0.16 \mathrm{~cm}\right.$, and $\tan \delta=$ $0.001)$ is $1610 \mathrm{MHz}$. To realize compact $\mathrm{H}$-shaped or ring MSA, slot of varying dimension is cut inside this RMSA. The $\mathrm{H}$-shaped MSA and its MN model are shown in Fig. 8(a, b). The input impedance for various slot dimensions obtained using IE3D and MNM as shown in Table 2, are in close agreement with each other. To reduce the number of segments present in MN model, an even mode network of H-shaped MSA is proposed as shown in Fig. 8(c). The even mode network consists of three segments and half the number of ports. The $Z_{\text {in }}$ calculated using even mode is in close agreement with that of MN model as given in Table 2 . Similarly ring MSA is analyzed using IE3D, MNM and even mode network models as shown in Fig. $9(\mathrm{a}-\mathrm{c})$. The $\mathrm{Z}_{\text {in }}$ and resonant frequency obtained using these methods are given in Table 3, which shows a close agreement between them.

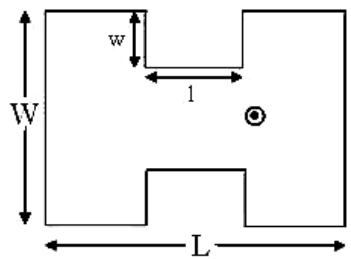

(a)

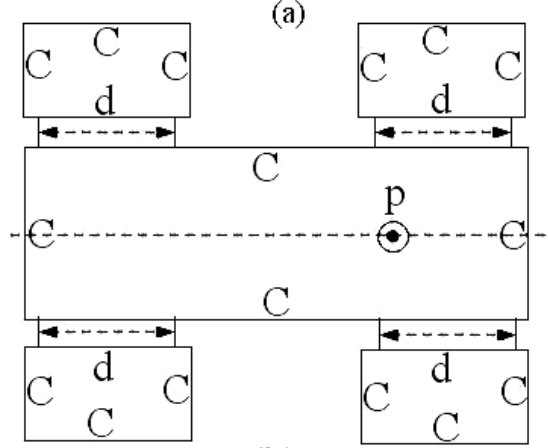

(b)

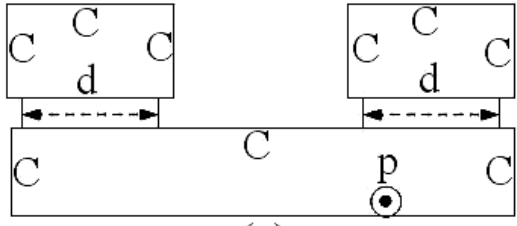

(c)

Fig. 8 (a) H-shaped MSA, its (b) MN model and its (c) Even mode network model

\section{CONCLUSIONS}

The MNM and even mode network model for RMSA is discussed. Further, the MN models for dual band step slot cut RMSA and triple band U-slot and rectangular slot cut stub loaded RMSAs are proposed. The MN model calculates the voltage distribution, which helps in understanding the excited mode on the patch. Further to reduce the complexity of MN model, an even mode network models of their MN models are proposed. The resonance frequencies, input impedance and voltage distribution obtained using even mode model closely agrees with that of the MN model as well as measured result. Further the MNM and even mode model of compact H-shaped 
and ring MSA is proposed. For these compact MSAs, a closer agreement is obtained between the two results. In addition to reducing the complexities of the $\mathrm{MN}$ model, an even mode method also reduces the computation time by $60 \%$. Although the computation time can be lowered using faster PCs. But since the even mode network model gives very close agreement with the simulated and measured result, for analyzing MSAs, only their even mode network models can be studied, which also reduces the coding program length.

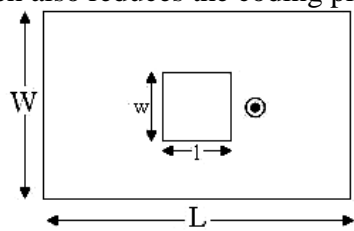

(a)

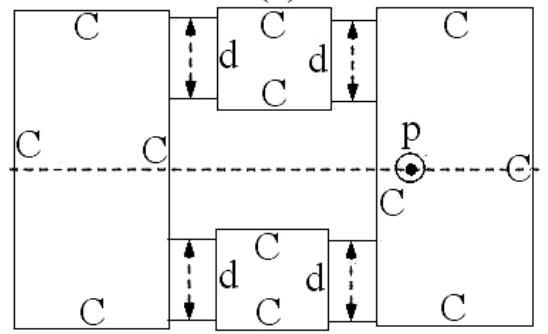

(b)

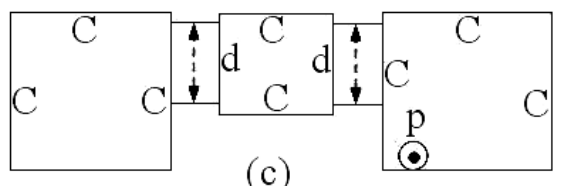

(c)

Fig. 9 (a) Ring MSA, its (b) MN model and its (c) Even mode network model

Table 1 - Comparison for resonance frequency and input impedance between IE3D, MNM and Even mode model for step slot cut RMSA

\begin{tabular}{|c|c|c|c|c|}
\hline \multirow[t]{2}{*}{$\begin{array}{l}\text { Method of } \\
\text { Analysis }\end{array}$} & \multicolumn{2}{|c|}{ Input impedance $(\Omega)$} & \multicolumn{2}{|c|}{$\begin{array}{c}\text { Resonance } \\
\text { frequency }(\mathrm{MHz})\end{array}$} \\
\hline & $\mathrm{f}_{1}$ & $\mathrm{f}_{2}$ & $\mathrm{f}_{1}$ & $\mathrm{f}_{2}$ \\
\hline IE3D & $\begin{array}{c}55.8-\mathrm{j} \\
0.21\end{array}$ & $\begin{array}{l}62.6-\mathrm{j} \\
0.16\end{array}$ & 661 & 893 \\
\hline MNM & $\begin{array}{c}57.6-\mathrm{j} \\
2.2\end{array}$ & $63-\mathrm{j} 8.3$ & 640 & 900 \\
\hline $\begin{array}{c}\text { Even mode } \\
\text { network }\end{array}$ & $\begin{array}{c}54.9-\mathrm{j} \\
5.6\end{array}$ & $\begin{array}{c}59.8-\mathrm{j} \\
0.33\end{array}$ & 640 & 900 \\
\hline
\end{tabular}

Table 2 - Comparison for resonance frequency and input impedance for $\mathrm{H}$-shaped MSA

\begin{tabular}{|c|c|c|c|c|c|}
\hline \multirow{2}{*}{$(\mathrm{cm})$} & \multicolumn{2}{|c|}{ IE3D } & \multicolumn{2}{c|}{ MNM } & $\begin{array}{c}\text { Even } \\
\text { mode }\end{array}$ \\
\cline { 2 - 5 } & $\begin{array}{c}\mathrm{f}_{\mathrm{r}} \\
(\mathrm{MHz})\end{array}$ & $\mathrm{Z}_{\text {in }}(\Omega)$ & $\begin{array}{c}\mathrm{f}_{\mathrm{r}} \\
(\mathrm{MHz})\end{array}$ & $\mathrm{Z}_{\text {in }}(\Omega)$ & \\
& & & & & $\mathrm{Z}_{\text {in }}(\Omega)$ \\
\hline $0.5 \mathrm{x}$ & 1526 & $56.8+$ & 1531 & $58.9+$ & $58.5+$ \\
0.5 & & $\mathrm{j} 0.5$ & & $\mathrm{j} 1.53$ & $\mathrm{j} 1.69$ \\
\hline $0.5 \mathrm{x}$ & 1361 & $75.3+$ & 1354 & $66.7+$ & $66.4-$ \\
1.0 & & $\mathrm{j} 1.2$ & & $\mathrm{j} 4.84$ & $\mathrm{j} 3.40$ \\
\hline $0.5 \mathrm{x}$ & 1124 & $76.4-$ & 1105 & $55.3+$ & $56.3-$ \\
1.5 & & $\mathrm{j} 3.7$ & & $\mathrm{j} 6.5$ & $\mathrm{j} 0.8$ \\
\hline
\end{tabular}

Table 3 - Comparison for resonance frequency and input impedance for ring MSA

\begin{tabular}{|c|c|c|c|c|c|}
\hline \multirow{2}{*}{ w x 1 } & \multicolumn{2}{|c|}{ IE3D } & \multicolumn{2}{c|}{ MNM } & $\begin{array}{c}\text { Even } \\
\text { mode }\end{array}$ \\
\cline { 2 - 5 } & $\mathrm{f}_{\mathrm{r}}(\mathrm{MHz})$ & $\mathrm{Z}_{\text {in }}$ & $\mathrm{f}_{\mathrm{r}}(\mathrm{MHz})$ & $\mathrm{Z}_{\text {in }}(\Omega)$ & \\
& & $(\Omega)$ & & & $\mathrm{Z}_{\text {in }}(\Omega)$ \\
& & & & & \\
\hline $0.5 \mathrm{x}$ & 1594 & $65.2-$ & 1602 & $67.7-$ & $67.6-$ \\
0.5 & & $\mathrm{j} 2.4$ & & $\mathrm{j} 2.9$ & $\mathrm{j} 3.3$ \\
& & & & & \\
\hline $1.0 \mathrm{x}$ & 1534 & $109-$ & 1542 & $107.5+$ & $106.7+$ \\
1.0 & & $\mathrm{j} 4.4$ & & $\mathrm{j} 3.4$ & $\mathrm{j} 2.6$ \\
& & & & & \\
\hline $1.5 \mathrm{x}$ & 1428 & $264+$ & 1426 & $266.3-$ & $265.4-$ \\
1.5 & & $\mathrm{j} 6.6$ & & $\mathrm{j} 11$ & $\mathrm{j} 12.6$ \\
\hline
\end{tabular}

\section{REFERENCES}

[1] Kumar, G., and Ray, K. P. 2003, Broadband Microstrip Antennas, First Edition, USA, Artech House

[2] Garg, R., Bhartia, P., Bahl, I., and Ittipiboon, A., Microstrip Antenna Design Handbook, 2001, Artech House, USA.

[3] Ray, K. P., and Kumar, G., Circular Microstrip Antennas with double stubs, Proceedings of ISRAMT99, Malaga, Spain, December 1999, pp. 381 - 384.

[4] Daniel, Asha E., Tunable dual band Rectangular Microstrip antennas and their Arrays, Ph.D. Thesis, 2006, I. I. T. Bombay, India

[5] Deshmukh, Amit A., and Ray, K. P., Multi-band Rectangular Microstrip Antennas, Microwave \& Opti. Tech. Letters, vol. 49, no. 11, Nov. 2007, pp. 2757 2761.

[6] Kumar, G., Broadband Microstrip Antennas using coupled resonators, Ph.D. Thesis, I.I.T. Kanpur, India, 1982.

[7] IE3D 12.1, 2004. Zeland Software, Freemont, USA

[8] Lu, J. H., Single Feed Dual Frequency Rectangular Microstrip Antenna With Pair Of Step Slots, Electronics Letters, vol. 35, no. 5, $4^{\text {th }}$ March 1999, pp. $354-355$. 